\title{
A cross-sectoral analysis of the relation between labor productivity and labor compensation in the European Union
}

\begin{abstract}
The aim of this paper is to assess and compare the link between labor productivity and compensation in four industries - air transport, electronics, finance, and telecommunications of twenty-five member states of the European Union (EU) from 2000 to 2014. The long-run and short-run dynamics of productivity and compensation are analyzed using the pooled mean group (PMG), the mean group (MG) and the dynamic fixed effects (DFE) estimators. The results confirm the existence of a gap between productivity and compensation in each of those industries as mentioned in previous studies. However, the results show that despite that gap, the link between the two variables is not broken. That is, productivity and compensation are not only linked in the long run, but they also return to their long-run equilibrium after every short-run disturbance. The econometric analysis also reveals that the relation between productivity and compensation does not follow a significantly different pattern from one industry to the other. These findings robust to alternative models, estimation techniques and across industries, suggest that there are some other cross-sectoral factors preventing productivity gains to be fully reflected on paychecks.
\end{abstract}

Keywords: wage; compensation; labor productivity; labor income share.

JEL classification: C33; E24; E25; J3.

\section{Introduction}

$\mathrm{N}$ eoclassical economic theory suggests that the remuneration of employees is equal to the marginal productivity of the market-clearing employee. Consequently, assuming that higher labor productivity is fully translated into higher wages, studies on wage determination usually extend the theoretical frameworks developed by Phillips (1958) and Blachflower, Oswald (1994) as they focus attention on the mitigating effect of unemployment (Nikulin, 2015).

Contrary to this orthodox economic approach, recent trends in many industries and economies reveal that productivity and pay have steadily diverged over the past decades. Brill et al. (2017) analyze the evolution of productivity and compensation in 183 U.S. industries between 1987 and 2015 and reveal that productivity outpaces pay in 77 percent of those industries. They also reveal that the largest gap between productivity and pay is found in industries with the largest productivity gains like the Information Technology industry. Pasimeni (2018) extends the scope of the analysis

1 Fofack, Achille Dargaud — Rauf Denktas University, Turkey; adfofack.irlaem@gmail.com.

Temkeng, Serge Djoudji — University of Buea, Cameroon; sdtemkeng.irlaem@gmail.com. 
to a panel of 34 developed countries over the last fifty years and confirms the existence of a significant gap between productivity and pay.

The observed gap between productivity and pay has led some scholars (Anderson, 2007; Bildirici, Alp, 2008; Pessoa, Van Reenen, 2012; Van Biesebroeck, 2015; Serrano, 2016; Ravikumar, Shao, 2016; ILO, 2016; Brill et al., 2017; Stansbury, Summers, 2017; Dosi et al., 2020; Schröder, 2020; Ioan, Ioan, 2020) to ask if the link between those two variables is not actually broken. Given the key role played by wages and labor market institutions in the construction of long-lasting economic activities, the steady gap between the growth rates of productivity and pay can lead to imbalances affecting not only inflation, interest rates, household consumption and aggregate demand, but also social justice (Summers, 2013; Van Biesebroeck, 2015; Pasimeni, 2018).

Those potential imbalances have led the scientific community to pay an increasing attention to the productivity-pay gap and to the factors sustaining it. Thus, among the possible causes of this gap, the literature (Van Biesebroeck, 2015; Brill et al., 2017; Stansbury, Summers, 2017) highlights the role played by technological progress and increased automation, education and skills, globalization and outsourcing, labor market institutions and regulation or asymmetric information and imperfect markets.

Reminding us that productivity and pay dynamics are not uniform across the economy, Brill et al. (2017) recommend focusing on a specific industry and studying its unique characteristics. In ine with that recommendation, this paper aims at assessing and comparing the link between productivity and pay in four industries (air transport, electronics, finance, and telecommunications) of twenty-five member states of the European Union (EU) from 2000 to 2014.

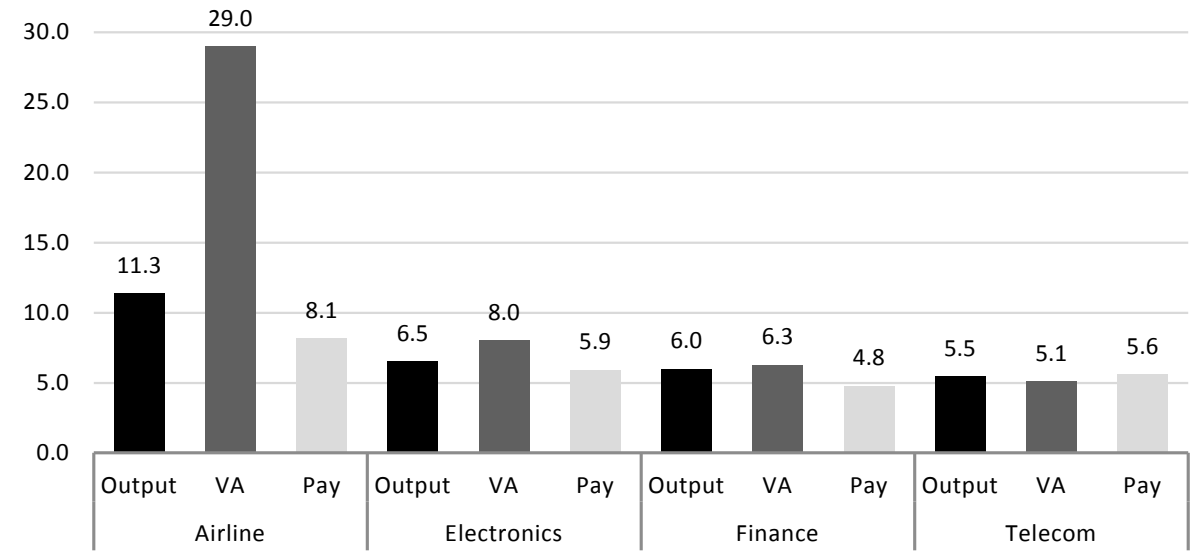

Fig. 1. Average growth rate of productivity and compensation

Note. All the variables are expressed in purchasing power parity. Output, VA and Pay stand for gross output per hour, gross value added per hour and labor compensation per hour, respectively.

Figure 1 shows the average growth rate of productivity (gross output and gross value added per hour worked) and compensation (per hour worked) in all four sectors. The figure reveals that in all sectors but one (telecom), compensation grows slower than productivity. Focusing on the average level of productivity and compensation in each industry and expressing average compensation as a percentage of average productivity, it is found that in all four industries, the compensation/productivity ratio is smaller when output accounts for productivity than when the latter 
is proxied with value added. Moreover, Figure 2 shows that the difference between the two compensation/productivity ratios ranges from $13.6 \%$ for telecom, $23.2 \%$ for finance, $32.5 \%$ for electronics to $52.4 \%$ for air transport.

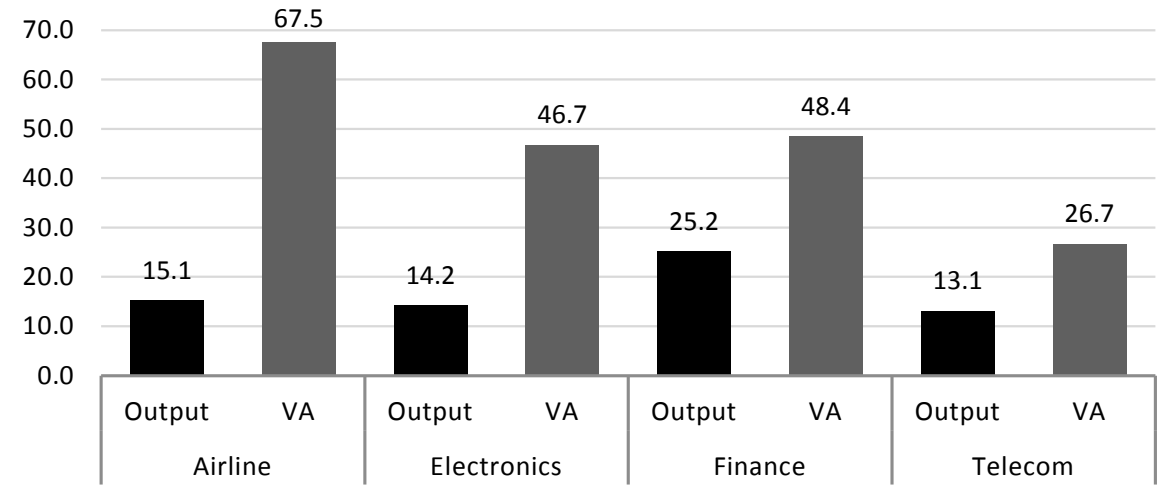

Fig. 2. Average compensation expressed as percentage of productivity Note. All the variables are expressed in purchasing power parity.

An in-depth analysis of the apparent heterogeneity of the relation between productivity and compensation across four EU sectors is carried out in this paper. For each sector, both the long-run and short-run dynamics of the two variables are analyzed using the pooled mean group (PMG), mean group (MG) and dynamic fixed effects (DFE) estimators. Moreover, different proxies of productivity are used since the variable accounting for the latter concept can substantially alter the findings of the paper. Finally, the robustness of the findings is tested with alternative models.

These four industries using different combinations of capital, labor, and technology and experiencing different levels of productivity are of interest because they provide a peculiar cross-sectoral view of productivity and pay dynamics. Further, the transnational dimension of the dataset, the specific characteristics of a customs union such as the EU, and the range of empirical tools used add to the novelty of the paper. The remainder of the paper is organized as follows: the next section describes the methodology; the main findings are presented in section 3 and discussed in section 4; and section 5 concludes the paper with some policy recommendations.

\section{Material and Method}

\subsection{Data}

To assess the link between productivity and pay in different economic sectors, data were collected from the World Input-Output Database (WIOD) ${ }^{2}$. The data set covers 4 industries ${ }^{3}$ and 25 EU countries $^{4}$ from 2000 to 2014 . Because of the rising importance of non-wage benefits like bonuses

2 See http://www.wiod.org/home.

3 The selected industries are: air transport (airline); finance service activities except insurance and pension funding (finance); manufacture of computers, electronic and optical products (electronics); and telecommunications (telecom).

4 Austria, Belgium, Bulgaria, Cyprus, Czech, Croatia, Denmark, Estonia, Finland, France, Germany, Greece, Hungary, Ireland, Italy, Luxembourg, Latvia, Netherland, Portugal, Poland, Romania, Slovakia, Slovenia, Sweden, and Spain. 
and other allowances and in line with the ILO (2016) and Pasimeni (2018), total labor compensation accounts for pay. Moreover, as recommended by Van Biesebroeck (2015), the variable is divided by the number of hours worked rather than the number of workers. Finally, the figures in local currencies are made comparable by using the purchasing power parity (PPP) conversion factor obtained from the World Bank.

Gross output and value added both account for productivity. The variables are also divided by the number of hours worked and converted to U.S. dollar. Moreover, as represented in Table 1, a control variable (the level of employment) is taken into consideration because it alters bargaining dynamics and reflects economic cycles (Stansbury, Summers, 2017). Finally, all the variables are transformed into logarithm for the estimated coefficients to be interpreted as elasticities.

Table 1. Description of variables

\begin{tabular}{lll}
\hline Variable & \multicolumn{1}{c}{ Definition } & Source \\
\hline Pay & Log of compensation of employees per hour worked in PPP & WIOD \\
Output & Log of gross output per hour worked in PPP & WIOD \\
Value added & Log of gross value added per hour worked in PPP & WIOD \\
Employment & Log of total number of hours worked by employees & WIOD \\
\hline
\end{tabular}

\subsection{Method}

Based on the theoretical framework developed by Stansbury and Summers (2017), let us suppose the relation between productivity and pay is described by the following autoregressive distributive lag (ARDL) model:

$$
\text { Pay }_{i t}=\sum_{j=1}^{p} \alpha_{i j} \text { Pay }_{i, t-j}+\sum_{j=0}^{q} \beta_{i j}^{\prime} \text { Productivity }_{i, t-j}+\gamma_{i}+\varepsilon_{i t},
$$

where $i$ and $t$ stand for countries and years, respectively. $\gamma_{i}$ represents country-specific fixed effects and $\varepsilon_{i t}$ is the residual. Equation (1) can be written in the form of an error correction model:

$\Delta$ Pay $_{i t}=\vartheta_{i}\left(\right.$ Pay $_{i, t-1}-\theta_{i}^{\prime}$ Productivity $\left._{i t}\right)+\sum_{j=1}^{p-1} \alpha_{i j}^{*} \Delta$ Pay $_{i, t-j}+\sum_{j=0}^{q-1} \beta_{i j}^{\prime *} \Delta$ Productivity $_{i, t-j}+\gamma_{i}+\varepsilon_{i t}$,

where $\vartheta_{i}=-\left(1-\sum_{j=1}^{p} \alpha_{i j}\right), \theta_{i}=\sum_{j=0}^{q} \beta_{i j} /\left(1-\sum_{k=1}^{p} \alpha_{i k}\right), \alpha_{i j}^{*}=-\sum_{m=j+1}^{p} \alpha_{i m}, j=1,2, \ldots, p-1$,

and $\beta_{i j}^{*}=-\sum_{m=j+1}^{q} \beta_{i m}, j=1,2, \ldots, q-1$.

The vector $\theta_{i}^{\prime}$ contains the long-run parameters while $\vartheta_{i}$ represents the speed of adjustment. This latter coefficient is expected to be negative and significant for the variables to exhibit a return to a long-run equilibrium. The relationship between productivity and pay is assessed using 
three different approaches: the pooled mean group (PMG) estimator, the mean group (MG) estimator and the dynamic fixed effects (DFE) estimator.

In the case of the DFE estimator, data for each country are pooled and only the intercepts can vary across countries. Blackburne and Frank (2007) argue that pooling the data like this produces inconsistent results when the slope parameters are not identical. This inconsistency led Pesaran and Smith (1995) to develop an alternative approach (the MG estimator) in which the intercepts, slope parameters and error variances can vary across countries. In this MG approach, the model is estimated for each country and the arithmetic average of the parameters is computed. Pesaran, Shin and Smith $(1997,1999)$ even go further by combining the pooling and averaging features of the DFE and the MG. They develop the PMG approach in which the intercepts, short-run parameters and error variances can vary across countries while the long-run coefficients are constrained to be equal across countries.

\section{Results}

Before any analysis, the stationarity of the data is tested using the unit root test developed by Im, Pesaran and Shin $(2003)^{5}$. The results reported in Table 2 show that the variables are not stationary at level but at their first difference.

The correlation between the variables is assessed and the results reported in Table 3 . Those results reveal that in all 4 industries, there is a positive and significant correlation between pay and the proxies of productivity. In the case of air transport and electronics, the correlation coefficient between pay and productivity changes substantially depending on the proxy used (output or value added) while this is not the case for finance and telecom. Thus, the correlation coefficient between pay and output is substantially higher than that between pay and value added in air transport while it is the inverse in electronics.

Table 2. Panel unit root tests

\begin{tabular}{|c|c|c|c|c|c|c|c|c|}
\hline & \multicolumn{2}{|c|}{ Airline } & \multicolumn{2}{|c|}{ Electronics } & \multicolumn{2}{|c|}{ Finance } & \multicolumn{2}{|c|}{ Telecom } \\
\hline & I & TI & I & TI & I & TI & I & TI \\
\hline \multicolumn{9}{|c|}{ Level } \\
\hline Productivity & 1.27 & $-2.44 * *$ & 0.33 & $-2.36 * *$ & 2.08 & $-1.82 * *$ & $-2.16^{* *}$ & 0.25 \\
\hline Pay & 0.39 & $-2.31 * *$ & 1.76 & $-1.73 * *$ & 0.92 & -1.56 & 1.18 & -0.35 \\
\hline Value_Added & 0.14 & $-1.88 * *$ & 0.76 & $-3.28 * *$ & 0.64 & -1.12 & $-4.78 * *$ & -1.38 \\
\hline Employment & -0.44 & -0.04 & 1.49 & $-2.08 *$ & $-1.75^{* *}$ & 1.27 & 0.57 & $-2.13^{* *}$ \\
\hline \multicolumn{9}{|c|}{ First difference } \\
\hline Productivity & $-11.28 * *$ & $-7.84 * *$ & $-10.81 * *$ & $-8.65 * *$ & $-11.21 * *$ & $-8.72 * *$ & $-8.00 * *$ & $-6.31 * *$ \\
\hline Pay & $-11.92 * *$ & $-12.47 * *$ & $-13.13^{* *}$ & $-9.29 * *$ & $-12.83 * *$ & $-9.17 * *$ & $-9.04 * *$ & $-8.88 * *$ \\
\hline Value_Added & $-14.81 * *$ & $-10.87 * *$ & $-12.06^{* *}$ & $-9.72 * *$ & $-10.43 * *$ & $-8.34 * *$ & $-8.75^{* *}$ & $-9.10 * *$ \\
\hline Employment & $-8.49 * *$ & $-6.74 * *$ & $-10.41 * *$ & $-7.10^{* *}$ & $-5.13 * *$ & $-4.81 * *$ & $-8.57 * *$ & $-6.68^{* *}$ \\
\hline
\end{tabular}

Note. ${ }^{* *}$ denotes significance at the 5 percent level. I and TI stand for intercept and trend and intercept, respectively.

5 The lag length is automatically selected based on Akaike information criterion. 
Table 3. Correlation matrix

\begin{tabular}{lcccc}
\hline & Pay-Airline & Pay-Electronics & Pay-Finance & Pay-Telecom \\
\hline Output & $0.823^{* *}$ & $0.670^{* *}$ & $0.820^{* *}$ & $0.880^{* *}$ \\
Value added & $0.638^{* *}$ & $0.866^{* *}$ & $0.862^{* *}$ & $0.861^{* *}$ \\
\hline
\end{tabular}

Note. $* *$ denotes significance at the 5 percent level.

The long-run relationship between productivity and pay is then tested using both Kao (EngleGranger based $)^{6}$ and Johansen-Fisher cointegration tests. The results presented in Table 4 reveal that for each industry, the null hypothesis of no cointegration is rejected in both tests. It can thus be concluded that there is a long-run relationship between productivity and compensation in each of those economic sectors. The robustness of that long-run relationship is tested with value added and the results reported in Table 5 confirm that there is a long-run relationship between productivity and compensation in each of those economic sectors. In these tables ADF stands for Augmented Dickey-Fuller test, and HAC stands for Heteroskedasticity and Autocorrelation Consistent.

Table 4. Panel cointegration tests - baseline model with output

\begin{tabular}{lcccc}
\hline & Airline & Electronics & Finance & Telecom \\
\hline \multirow{2}{*}{ ADF } & & Kao residual cointegration test & & $-3.849^{* *}$ \\
Residual variance & $-4.405^{* *}$ & $-2.549^{* *}$ & $-7.501^{* *}$ & 0.007 \\
HAC variance & 0.027 & 0.015 & 0.004 & 0.011 \\
\hline \multicolumn{5}{c}{ Johansen-Fisher cointegration test } \\
None & 0.019 & Trace & Trace & Trace \\
At most 1 & - & $130.7^{* *}$ & $155.8^{* *}$ & $139.6^{* *}$ \\
\hline
\end{tabular}

Note. ${ }^{* *}$ denotes significance at the 5 percent level.

Table 5. Panel cointegration tests — baseline model with value added

\begin{tabular}{|c|c|c|c|c|}
\hline & Airline & Electronics & Finance & Telecom \\
\hline \multicolumn{5}{|c|}{ Kao residual cointegration test } \\
\hline $\mathrm{ADF}$ & $-1.613 * *$ & $-2.494 * *$ & $-5.172 * *$ & $-4.614 * *$ \\
\hline Residual variance & 0.038 & 0.069 & 0.005 & 0.005 \\
\hline HAC variance & 0.035 & 0.038 & 0.005 & 0.006 \\
\hline \multicolumn{5}{|c|}{ Johansen-Fisher cointegration test } \\
\hline & Trace & Trace & Trace & Trace \\
\hline None & $135.9 * *$ & $113.9 * *$ & $130.4 * *$ & $154.4 * *$ \\
\hline At most 1 & $105.8^{* *}$ & $89.64 * *$ & $73.77 * *$ & $84.66^{* *}$ \\
\hline
\end{tabular}

Note. ${ }^{* *}$ denotes significance at the 5 percent level.

6 The lag length is automatically selected based on Akaike information criterion. 
The baseline model presented in equation (1) is estimated using the PMG, MG and DFE estimators with output as proxy for productivity. The results reported under M1, in Tables 6, 7, 8 and 9 reveal that in the long run and in each of the four industries, productivity has a positive and significant impact on pay. Moreover, this positive and significant impact is robust across estimation techniques. As for the short-run impact of output on pay, neither its sign nor its significance is robust across industries and estimation techniques. M1 also shows that the error correction term is negative and significant as expected. This finding is also robust across industries and estimation techniques and on average, the speed of adjustment is equal to $38.66 \%$ for air transport, $36.63 \%$ for finance, $23.00 \%$ for electronics and $22.36 \%$ for telecom.

The baseline model is extended with employment as control variable. The model is estimated and reported in M2. The results reveal that in the long run and in each of the four industries, productivity has a positive and significant impact on pay. As for the long-run impact of employment, its sign and its significance vary across sectors and estimation techniques. This is also the case for the short-run impact of output on pay meanwhile that of employment is negative and significant in most cases. Short-run dynamics also reveal that the error correction term is negative and significant with the speed of adjustment ranging from $44.30 \%$ for air transport, $42.40 \%$ for finance, $29.63 \%$ for electronics to $29.46 \%$ for telecom.

Additional robustness check is done with value added as proxy for productivity. The results reported in M3 reveal that in the long run and in each of the four industries, value added has a positive and significant impact on pay. This positive and significant impact is robust across estimation techniques while the sign and the significance of the long-run impact of employment are not. As for short-run dynamics, they reveal that employment has a negative, significant, and robust impact on pay in all four industries. Furthermore, the error correction term is found to be negative, significant, and robust while the speed of adjustment ranges from $31.23 \%$ for air transport to $26.5 \%$ for telecom.

Finally, Figure 3 summarizes the results reported in Table 6, 7, 8 and 9 by displaying for each industry, the average coefficient associated with the long-run impact of productivity (output and value added) on compensation and the speed of adjustment of adjustment of the error correction

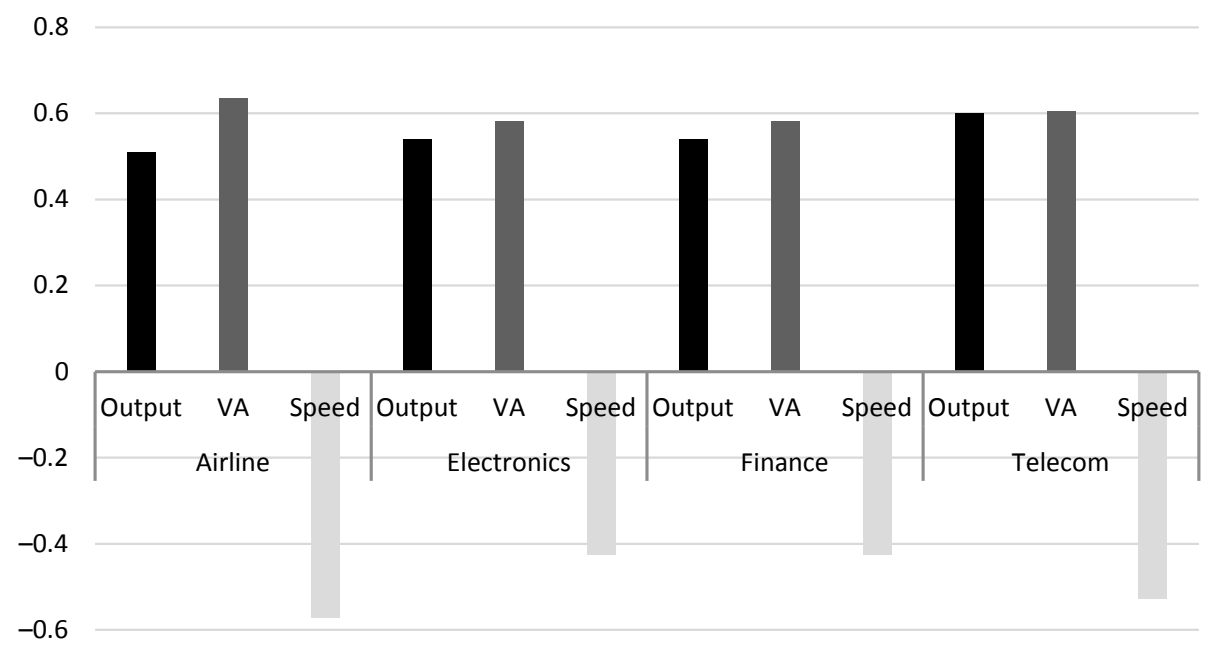

Fig. 3. Average coefficients per industry

Note. Output and VA account for the long-run impact of output and value added on compensation while speed stands for the short-run speed of adjustment. 

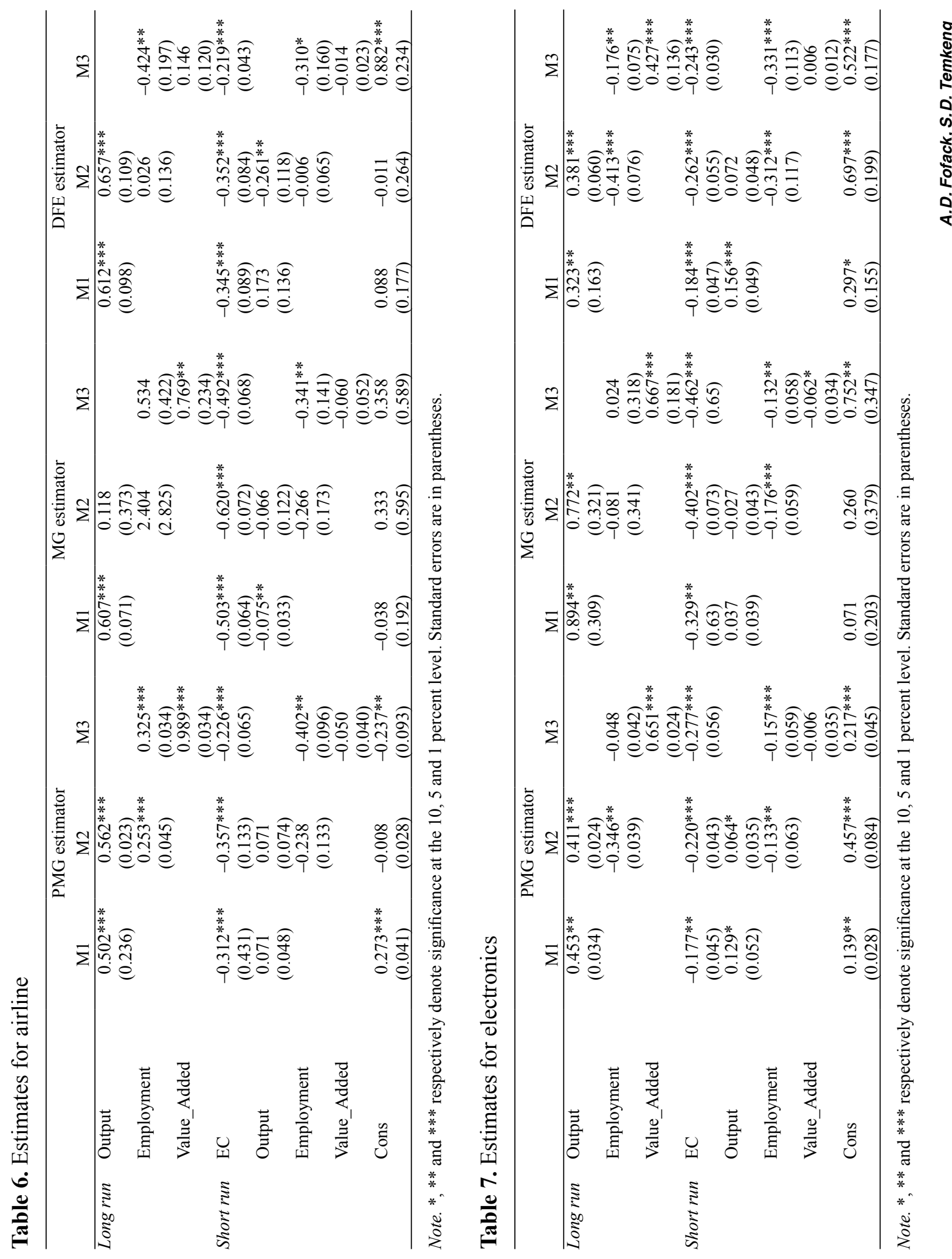


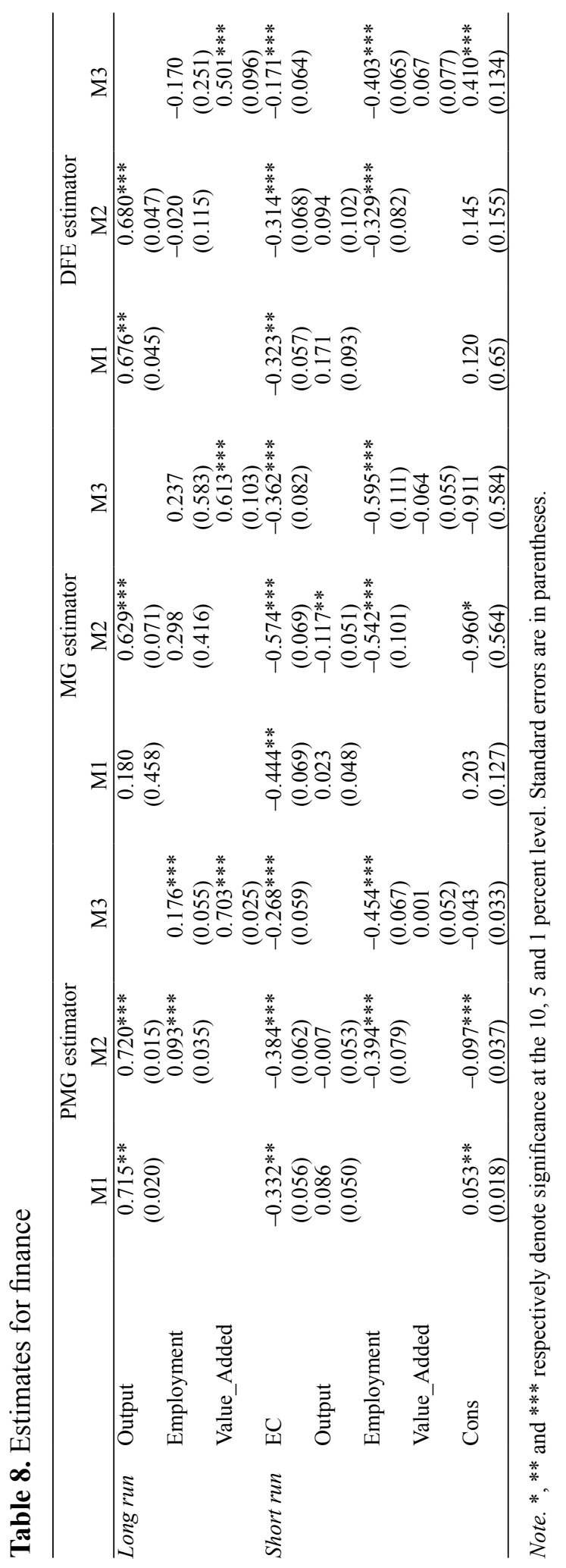

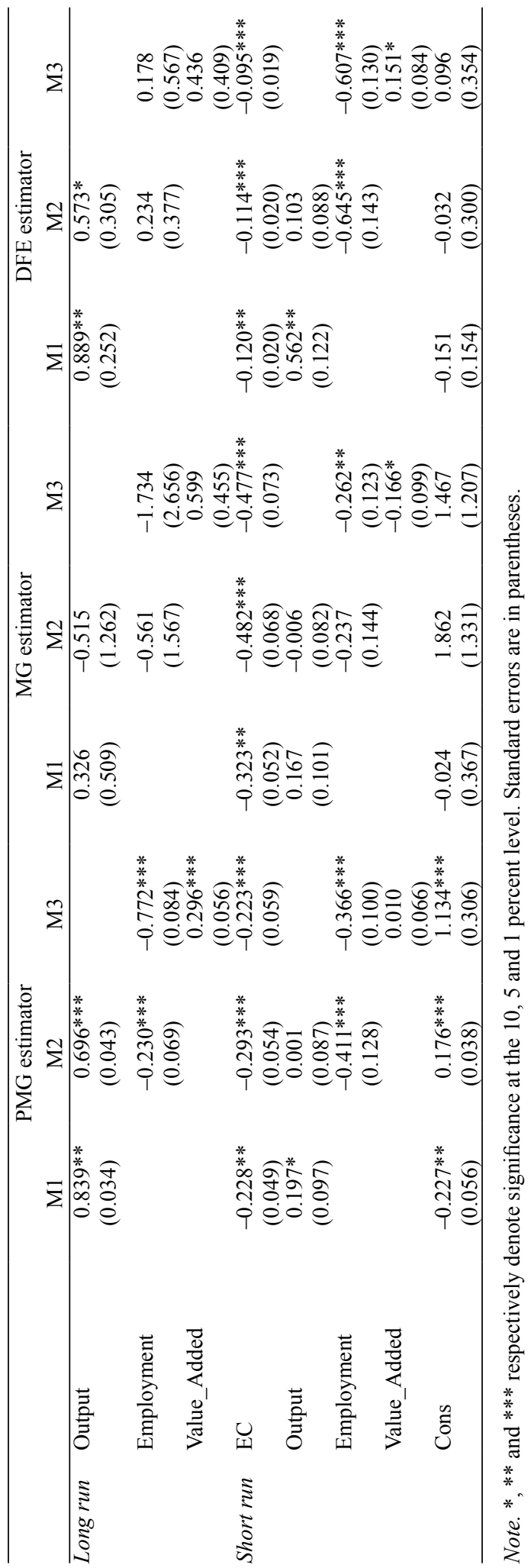


model. The figure shows that, in all four industries, the long-run impact of productivity on compensation is higher when value added accounts for the former. The figure also reveals that on average, the impact of productivity on compensation and the speed of adjustment of the error correction model tend to be higher for air transport and telecom than for electronics and finance. However, the figure shows that the relation between productivity and compensation does not follow a significantly different pattern from one industry to the other.

\section{Discussion}

In line with the literature, the correlation analysis shows a positive relationship between both proxies of productivity and pay. Thus, in all four industries, productivity and compensation increase together even though the correlation coefficient is inferior to one. As for the cointegration analysis, it reveals that productivity and compensation are linked in the long run but does not tell us how tight that link really is.

Estimation of the baseline model tells us more about the tightness of the link between productivity and compensation in each of those industries. The results show that an increase in productivity leads to a significant increase in compensation in the long run. Thus, a 1 percent increase in productivity leads to an average increase in pay equivalent to 0.68 percent for telecom, 0.56 percent for electronics, 0.57 percent for air transport and 0.52 percent for finance. These findings are in line with Pasimeni (2018) who studies 34 advanced economies and finds that the correlation between productivity and compensation varies between 0.6 and 0.8 .

Focusing on the short run, the results of the baseline model reveal that the error correction term is negative and significant as expected, confirming the long-run equilibrium between productivity and compensation. Adding employment to the baseline model, the results still show that an increase in productivity is associated with a significant increase in pay in the long. Short-run dynamics reveal that the error correction term is negative and significant. Moreover, it is also found that employment has a negative and significant impact on pay. This counter-intuitive finding could be explained by the fact that employment is an indicator of cyclical conditions often used for shortterm adjustments in the economy.

The robustness of those findings was further checked with an alternative specification in which value added is used as proxy for productivity. The results of this alternative specification essentially confirm those of the previous models as they suggest that there is positive and significant long-run relationship between productivity and pay in all four industries. Moreover, the results confirm that those two variables return to their long-run equilibrium after every short-run disturbance.

Overall, Tables $6,7,8$ and 9 confirm the existence of a gap between productivity and pay in all four industries. This gap is in line with previous studies (Anderson, 2007; Bildirici, Alp, 2008; Pessoa, Van Reenen, 2012; Van Biesebroeck, 2015; Serrano, 2016; Ravikumar, Shao, 2016; ILO, 2016; Brill et al., 2017; Stansbury, Summers, 2017; Dosi et al., 2020; Schröder, 2020; Ioan, Ioan, 2020). The results also tell us that despite that gap, the link between productivity and compensation is not broken. Indeed, productivity and pay are not only linked in the long run; but they also return to their long-run equilibrium after every short-run disturbance. Finally, the results reveal that the relation between productivity and compensation does not follow a significantly different pattern from one industry to the other. 


\section{Conclusion}

Assessing and comparing the link between productivity and pay in four European industries, this paper provides a peculiar cross-sectoral view of productivity and pay dynamics. Further, the transnational dimension of the dataset, the specific characteristics of a customs union such as the EU, and the range of empirical tools used add to the novelty of the paper. The results confirm the existence of a gap between those two variables as mentioned in previous studies (Anderson, 2007; Bildirici, Alp, 2008; Pessoa, Van Reenen, 2012; Van Biesebroeck, 2015; Serrano, 2016; Ravikumar, Shao, 2016; ILO, 2016; Brill et al., 2017; Stansbury, Summers, 2017; Dosi et al, 2020; Schröder, 2020; Ioan, Ioan, 2020). The findings also tell us that despite that gap, the link between productivity and pay is not broken. That is, productivity and pay are not only linked in the long run; but they also return to their long-run equilibrium after every short-run disturbance. Moreover, the results reveal that the relation between productivity and compensation does not follow a significantly different pattern from one industry to the other. These findings robust to alternative models, estimation techniques and across industries suggest after Stansbury and Summers (2017) that there are some other factors preventing productivity gains to be reflected on paychecks.

Considering both the key role played by wages and labor market institutions in the construction of long-lasting economic activities and the potential imbalances (in terms of inflation, interest rates, household consumption, aggregate demand and social justice) that the productivity-pay gap can bring about, suitable policies should be developed and implemented to close this gap. In that vein, the OECD (2018) proposes to strengthen collective bargaining institutions and improve the bargaining position of workers. The implementation of such a policy will, in theory, lead to higher wages and an increase in the labor share.

Herr and Kazandziska (2011) argue that the implementation of wage norm could help close the productivity-compensation gap. According to this norm, wages adjustments should follow not only medium-term changes in productivity but also the target inflation rate set by the central bank. Thus, productivity gains are channeled into wages and the purchasing power of workers is preserved. Finally, given that the literature (Van Biesebroeck, 2015; Brill et al., 2017; Stansbury, Summers, 2017) highlights the role played by technological progress and increased automation, education and skills, globalization and outsourcing, labor market institutions and regulation or asymmetric information and imperfect markets, any policy mitigating the impact of one or many of those factors is also suitable to close the gap between productivity and pay in those four industries.

\section{References}

Anderson R. (2007). How well do wages follow productivity growth? Economic Synopses, No 7.

Bildirici M., Alp E. (2008). The relationship between wages and productivity: TAR unit root and TAR cointegration. International Journal of Applied Econometrics and Quantitative Studies, 5 (1), 94-110.

Blachflower D., Oswald A. (1994). The wage curve. Cambridge, London: MIT Press.

Blackburne E., Frank M. (2007). Estimation of nonstationary heterogeneous panels. The Stata Journal, 7 (2), 197-208.

Brill M., Holman C., Morris C., Raichoudhary R., Yosif N. (2017). Understanding the labor productivity and compensation gap. Beyond the Numbers: Productivity, 6 (6), 1-14. 
Dosi G., Virgillito M., Yu X. (2020). The wage-productivity nexus in the world factory economy. World Development, 129, 104875.

Herr H., Kazandziska M. (2011). Principles of minimum wage policy - economics, institutions and recommendations. GLU Working Paper, 11.

ILO. (2016). Wages, productivity and labour share in China. ILO Regional Office for Asia and the Pacific Research Note, April 2016.

Im K., Pesaran M., Shin Y. (2003). Testing for unit roots in heterogeneous panels. Journal of Econometrics, $115(1), 53-74$.

Ioan C., Ioan G. (2020). The dependence of net average wage on labour productivity in Romania. EuroEconomica, 1 (39), 7-47.

Nikulin D. (2015). Relationship between wages, labour productivity and unemployment rate in new EU member countries. Journal of International Studies, 8 (1), 31-40.

OECD. (2018). Decoupling of wages from productivity: What implications for public policies? OECD Economic Outlook, 2, 51-65.

Pasimeni P. (2018). The relation between productivity and compensation in Europe. European Economy Discussion Papers, 079.

Pesaran M., Shin Y., Smith R. (1997). Estimating long-run relationships in dynamic heterogeneous panels. Cambridge Working Papers in Economics, 9721.

Pesaran M., Shin Y., Smith R. (1999). Pooled mean group estimation of dynamic heterogeneous panels. Journal of the American Statistical Association, 94 (446), 621-634.

Pesaran M., Smith R. (1995). Estimating long-run relationships from dynamic heterogeneous panels. Journal of Econometrics, 68 (1), 79-113.

Pessoa J., Van Reenen J. (2012). Decoupling of wage growth and productivity growth? Myth and reality. Resolution Foundation.

Phillips A. (1958). The relation between unemployment and the rate of change of money wage rates in the United Kingdom, 1861-1957. Economica, 25, 283-299.

Ravikumar B., Shao L. (2016). Labor compensation and labor productivity: Recent recoveries and the long-term trend. Economic Synopses, 16.

Schröder J. (2020). Decoupling of labour productivity growth from median wage growth in Central and Eastern Europe. Research Report, 448. The Vienna Institute for International Economic Studies.

Serrano M. (2016). The (missing) link between wages and productivity in the Philippines: What role for collective bargaining and the new two-tier wage system? Conditions of Work and Employment Series, 59. ILO.

Stansbury A., Summers L. (2017). Productivity and pay: Is the link broken? NBER Working Paper, 24165

Summers L. (2013). IMF Economic Forum: Policy responses to crises. Speech at the IMF Annual Research Conference, November $8^{\text {th }}, 2013$.

Van Biesebroeck J. (2015). How tight is the link between wages and productivity? A survey of the literature. Conditions of Work and Employment Series, 54. ILO.

Received 21.07.2020; accepted 09.04.2021. 